\title{
A Review on Scheduling in Cloud Computing
}

\author{
Sujitha.A ${ }^{1}$, Gunasekar.K ${ }^{2}$ \\ ${ }^{1}$ M.E.Scholar, Department of Computer Science \& Engineering, Nandha Engineering \\ College, Erode-638052, Tamil Nadu, India \\ ${ }^{2}$ Associate Professor, Department of Computer Science \& Engineering, Nandha \\ Engineering College, Erode-638052, Tamil Nadu, India
}

\begin{abstract}
Cloud computing is the requirement based on clients that this computing which provides software, infrastructure and platform as a service as per pay for use norm. The scheduling main goal is to achieve the accuracy and correctness on task completion. The scheduling in cloud environment which enables the various cloud services to help framework implementation. Thus the far reaching way of different type of scheduling algorithms in cloud computing environment surveyed which includes the workflow scheduling and grid scheduling. The survey gives an elaborate idea about grid, cloud, workflow scheduling to minimize the energy cost, efficiency and throughput of the system.
\end{abstract}

\section{KEYWORDS}

\section{Cloud Computing, Scheduling, Virtualization}

\section{INTRODUCTION}

Cloud computing is also referred as on-demand computing, is a kind of Internet-based computing that provides resources sharing and data to computers and other devices on demand. It relies on sharing of resources to achieve integrity and scale of economy, resemble to a utility computing. Cloud computing has become a highly demanded service due to the benefit of high computing power, monetary cost, high performance, availability ,scalability along with accessibility. There was several cloud vendors are experiencing growth rates of $50 \%$ per year, but being still in a stage of inception, it has risk that have to be focused to make cloud computing services more reliable and user friendly. The figure 1 is about the cloud computing services.

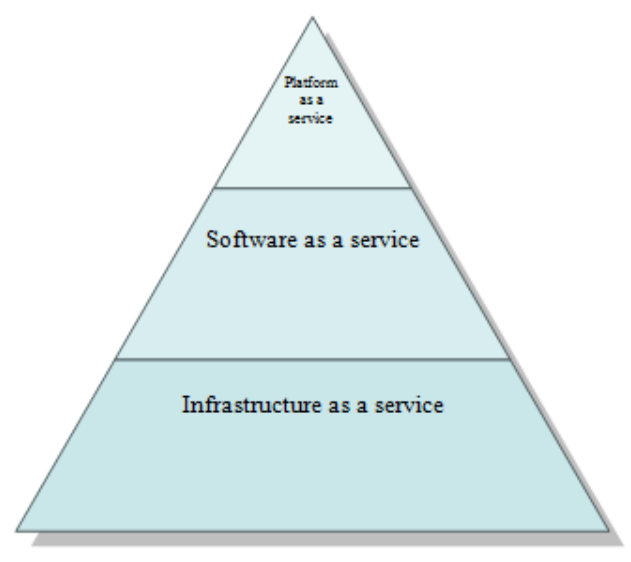

Figure 1 Cloud Computing Services 
Virtualized resources with an under utilization rate which consume an unsatisfactory amount of energy compared to the energy consumption of a completely utilized cloud computing. According to [13], energy consumption of an idle resource is about as $60 \%$ or peak power. In cloud computing, there is a connection between energy consumption and resource utilization. An effective technique is Task consolidation which is incredibly enabled by virtualization technologies, which aid the concurrent execution of several tasks, harness resource utilization and in turn reduce the energy consumption [1].

\section{OVERVIEW}

\subsection{Scheduling}

The cloud computing is effective based on the scheduling. Based on various parameters the task is to be scheduled such as arrival time, system load, execution time and deadline. It makes the task to finish on time and which guarantee the clients to improve flexibility in cloud and reliability of systems in cloud. The tasks are uncertain, so scheduling is deployed to overcome the uncertainty [13].

\subsection{Virtualization}

Virtualization technology is responsible for the creation, migration and cancellation of virtual machines [8]. When the task needs space in excess, fluctuation in utilization of resources leads to migration. Virtualization carries out the load balancing, consolidation, and hot spot mitigation [11]. It allocates data center resources dynamically based on the demands given by the user and number of servers is to be reduced to bloom out the green computing. The figure 2 describes the work of virtualization technology.

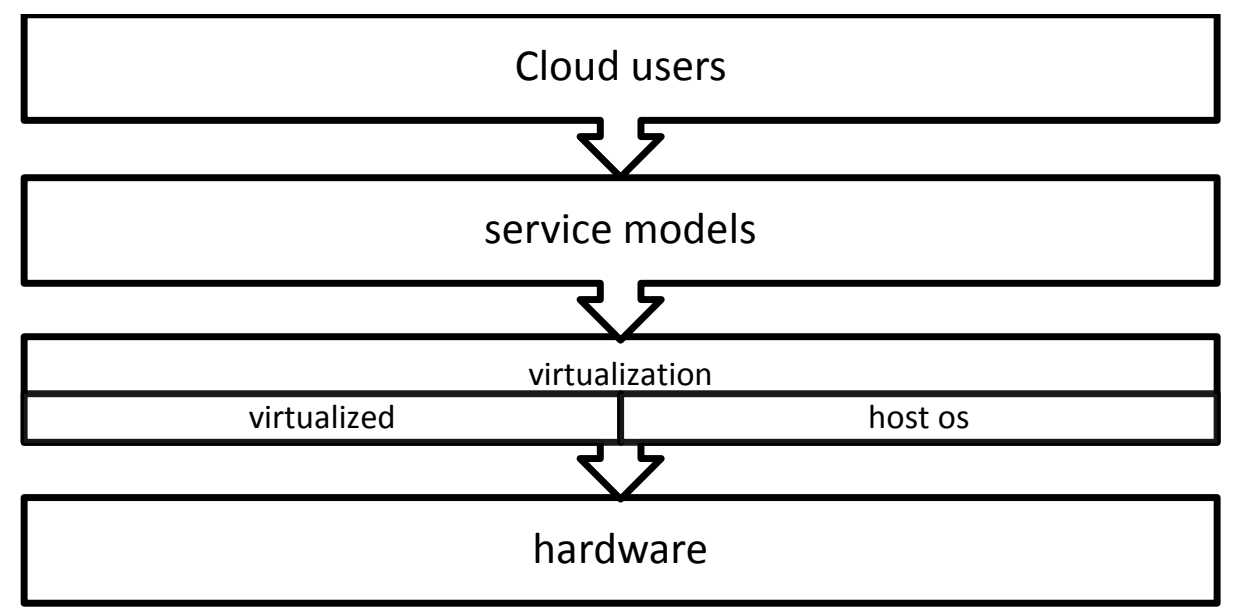

Figure 2 the Work of Virtualization Technology

\section{LITERATURE SURVEY}

\section{A Cloud Gaming System Based on User-Level Virtualization}

Author focused on the cloud gaming. Cloud gaming renders an interactive gaming application in the cloud and streams the scenes as a video sequence to the player over Internet. Author proposed GCloud, a GPU/CPU hybrid cluster for cloud gaming based on the user-level virtualization technology. Deployed a performance model to analyze the server-capacity and games' resourceconsumptions, which sort by type into two games: CPU-critical and memory-io-critical. 
Simulation tests evident that both of the First-Fit-like and the Best-Fit-like strategies outrun the other(s). Test results indicate that GCloud is efficient.

\section{ANGEL: Agent-Based Scheduling for Real-Time Tasks}

Author devised a novel agent-based scheduling mechanism [7] in cloud computing environment to assign real-time tasks and dynamically provision resources. A bidirectional announcementbidding mechanism and the collaborative processes employed consist of three phases. The three phases are basic matching phase, forward announcement-bidding phase and backward announcement-bidding phase. In a meanwhile, author designs both forward and backward announcement-bidding phases for calculation rule of the bidding values and two heuristics for selecting contractors. The bidirectional announcement-bidding mechanism is used to propose an agent-based dynamic scheduling algorithm named ANGEL for real-time, separate and aperiodic tasks in clouds. Extensive experiments are conducted on cloudsim platform.

\section{An Energy-Saving Task Scheduling Strategy Based on Vacation Queuing Theory}

High energy consumption [15] is one of the major issues of cloud computing systems. Requested jobs in cloud computing environments have the nature of changeability, and gauge nodes have to be powered on all the time to await requested tasks. This results in an incredible wastage of energy. Task scheduling algorithm of an energy-saving based on the vacation queuing model for cloud computing systems is proposed here. No of computer nodes, total idle energy, the number of tasks arriving at the system, heuristic task scheduling algorithms, the meta-heuristic task scheduling algorithms, the queuing theory-based algorithms used here. Simulation results evident that the proposed algorithm can ensure task performance, while reducing the energy cost of a cloud computing system effectively.

\section{Exploring Blind Online Scheduling for Mobile cloud}

Mobile cloud is a technology through the enabled users will enjoy abundant multimedia applications in a computing environment. An important issue for the mobile cloud is the scheduling of massive multimedia flows with heterogeneous QoS guarantee. Multimedia servers based on the slot information of the users' requests that occurs on last time, and route all the multimedia flows according to the first-come first-served rule. Operating time of schedule, User waiting time, Performance improvement time is used to measure the performance of the system. Blind online scheduling algorithm (BOSA) [2] is used here. Mobile Cloud Multimedia Services (MCMS) are the environmental tool. Simulation results shows that the proposed scheme can efficiently schedule heterogeneous multimedia flows to satisfy dynamic QoS requirements in a practical mobile cloud.

\section{Temporal Load Balancing with Energy Cost Optimization}

A cloud computing service plays a vital role in people's daily life. These services are encouraged by infrastructure known as Internet data center (IDC) [1]. As demand for cloud computing services sounds, energy consumed by IDCs is blown forward. Workload intensity, Queuing delay, Energy costs are used to measure the performance. Eco-IDC Minimize energy cost algorithm used here. Eco-IDC Minimize energy cost Service delay avoidance as a result of this technique.

\section{A Hyper-Heuristic Scheduling Algorithm for Cloud}


Rule-based scheduling algorithms have been used on vast cloud computing systems because they are simple and easy to implement. There are a lot of areas to improve these algorithms performance, notably by using heuristic scheduling. A novel heuristic scheduling algorithm is called hyper-heuristic scheduling algorithm (HHSA) [5] which is used to find better scheduling solutions for cloud computing systems. Result shows that it reduce the make span of task scheduling compared with the other scheduling algorithms.

\section{FESTAL: Fault-Tolerant Elastic Scheduling Algorithm for Real-Time Tasks in Virtualized Clouds}

Fault tolerance in clouds receives an attention in both industry and academia mainly for real-time applications due to their safety critical nature. Researches on the fault-tolerant scheduling [16] study the virtualization and the elasticity is the two key features of clouds. To address this issue, author presents a fault-tolerant mechanism which extends the primary-backup model to incorporate the features of clouds. Host, Time, Task count, Interval time are used to measure the performance of the system. An efficient fault-tolerant elastic scheduling algorithm FESTAL NonMigration-FESTAL (NMFESTAL), Non-Overlapping-FESTAL (NOFESTAL),Elastic First Fit (EFF). FESTAL is able to achieve both fault tolerance and high performance in terms of resource utilization.

\section{Virtual Machine Scheduling for Improving Energy Efficiency in IAAS Cloud}

Author leveraged a VM scheduling scheme encounter resource constraints, like the physical server size (CPU, memory, storage, bandwidth, etc.) and capacity of network link to minimize both the numbers of active PMs and network elements so as to finally reduce energy consumption. Numbers of VM, Total energy consumption, changing traffic between VM are used to measure the performance of the system. VM-Mig algorithms [19] are used here.

\section{Evolutionary Multi-Objective Workflow Scheduling in Cloud}

An already established workflow scheduling algorithms in classic distributed or heterogeneous computing environments, it arise some issues in being directly applied to the Cloud environments. To solve this workflow scheduling problem on an infrastructure as a service (IAAS) platform, they used an evolutionary multi-objective optimization (EMO)-based algorithm [6]. Time, Cost, Runtime ratio are used to measure the performance of the system. An evolutionary multi-objective optimization (EMO)-based algorithm is used. The result of this paper solves the multi-objective Cloud scheduling problem which minimizes both make span and cost simultaneously.

\section{Scheduling in Compute Cloud with Multiple Data Banks Using Divisible Load Paradigm}

Author leveraged that to design a scheduling strategy for heterogeneous computing resources with shared data banks is challengeable one [9]. The compute cloud environment is used to reduce the total processing time. No of processors, processing time, No of workers role are used to measure the performance. In order to divisible load theory, the scheduling challenge is formulated as relevant recursive equations and constraints. In that are derived from the continuity of processing time because retrieval from multiple data banks. The scheduling problem in a compute cloud is equated as a linear programming problem. One is to utilize the best possible use of available productive resources, and the other is to solve complex problems by splitting them into solvable parts. 


\section{4. comparisons on different scheduling techniques}

\begin{tabular}{|c|c|c|c|}
\hline TITLE & ALGORITHM & PARAMETER & CONCLUSION \\
\hline $\begin{array}{l}\text { A Cloud Gaming System } \\
\text { Based on User-Level } \\
\text { Virtualization }\end{array}$ & $\begin{array}{l}\text { Gcloud, a } \\
\text { GPU/CPU hybrid } \\
\text { cluster }\end{array}$ & $\begin{array}{l}\text { Server number } \\
\text { Total game requests }\end{array}$ & $\begin{array}{l}\text { Balance the gaming- } \\
\text { responsiveness, costs }\end{array}$ \\
\hline $\begin{array}{l}\text { Temporal Load Balancing } \\
\text { with Energy Cost } \\
\text { Optimization }\end{array}$ & Eco-IDC & $\begin{array}{l}\text { Workload intensity } \\
\text { Queuing delay } \\
\text { Energy cost }\end{array}$ & $\begin{array}{l}\text { Energy cost reduction for } \\
\text { IDC -Alleviates } \\
\text { workload drop. }\end{array}$ \\
\hline $\begin{array}{l}\text { ANGEL: Agent-Based } \\
\text { Scheduling for Real-Time } \\
\text { Tasks }\end{array}$ & $\begin{array}{l}\text { Dynamic } \\
\text { scheduling } \\
\text { Algorithm- } \\
\text { ANGEL }\end{array}$ & $\begin{array}{l}\text { Task count } \\
\text { Task Guarantee ratio }\end{array}$ & $\begin{array}{l}\text { It addresses the issue of } \\
\text { schedulability, } \\
\text { Priority,scalability, real- } \\
\text { time in virtualized cloud } \\
\text { environment. }\end{array}$ \\
\hline $\begin{array}{l}\text { An Energy-Saving Task } \\
\text { Scheduling Strategy } \\
\text { Based on Vacation } \\
\text { Queuing Theory }\end{array}$ & 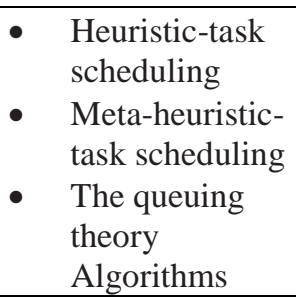 & $\begin{array}{l}\text { No of computer } \\
\text { nodes } \\
\text { Total idle energy } \\
\text { The number of tasks } \\
\text { arriving at the system }\end{array}$ & $\begin{array}{l}\text { It ensure task performance, } \\
\text { reducing } \\
\text { The energy cost of a cloud } \\
\text { computing system } \\
\text { effectively. }\end{array}$ \\
\hline $\begin{array}{l}\text { Scheduling in Compute } \\
\text { Cloud with Multiple Data } \\
\text { Banks Using Divisible } \\
\text { Load Paradigm }\end{array}$ & $\begin{array}{l}\text { Scheduling } \\
\text { Algorithm }\end{array}$ & $\begin{array}{l}\text { No of processors } \\
\text { Processing time } \\
\text { No of workers role }\end{array}$ & $\begin{array}{l}\text { It solve } \\
\text { Complex problems by } \\
\text { breaking them into } \\
\text { solvable parts. }\end{array}$ \\
\hline $\begin{array}{l}\text { Exploring Blind Online } \\
\text { Scheduling for Mobile } \\
\text { cloud }\end{array}$ & $\begin{array}{l}\text { Blind online } \\
\text { scheduling } \\
\text { Algorithm (BOSA) }\end{array}$ & $\begin{array}{l}\text { Operating time of } \\
\text { schedule } \\
\text { User waiting time } \\
\text { Performance } \\
\text { improvement time }\end{array}$ & $\begin{array}{l}\text { It reduce the delay and } \\
\text { Energy among the servers. }\end{array}$ \\
\hline $\begin{array}{l}\text { A Hyper-Heuristic } \\
\text { Scheduling } \\
\text { Algorithm for Cloud }\end{array}$ & $\begin{array}{l}\text { Hyper-heuristic } \\
\text { scheduling } \\
\text { algorithm (HHSA) }\end{array}$ & $\begin{array}{l}\text { Interaction } \\
\text { Best so far make span }\end{array}$ & $\begin{array}{l}\text { Reduce the make span of } \\
\text { task }\end{array}$ \\
\hline $\begin{array}{l}\text { Evolutionary Multi- } \\
\text { Objective Workflow } \\
\text { Scheduling in Cloud }\end{array}$ & $\begin{array}{l}\text { Evolutionary multi- } \\
\text { objective } \\
\text { optimization } \\
\text { (EMO)-based } \\
\text { algorithm }\end{array}$ & $\begin{array}{l}\text { Time } \\
\text { Cost } \\
\text { Runtime ratio }\end{array}$ & $\begin{array}{l}\text { Minimizes make span and } \\
\text { cost simultaneously }\end{array}$ \\
\hline $\begin{array}{l}\text { FESTAL: Fault-Tolerant } \\
\text { Elastic Scheduling } \\
\text { Algorithm for Real-Time } \\
\text { Tasks in Virtualized } \\
\text { Clouds }\end{array}$ & $\begin{array}{ll} & \text { FESTAL. } \\
\text { Non- } \\
\text { Migration- } \\
\text { FESTAL, } \\
\text { Non- } \\
\text { Overlapping- } \\
\text { FESTAL }\end{array}$ & $\begin{array}{l}\text { Host } \\
\text { Time } \\
\text { Task count } \\
\text { Interval time } \\
\text { Tools: } \\
\text { Cloudsim }\end{array}$ & $\begin{array}{l}\text { FESTAL is able to } \\
\text { Achieve both fault } \\
\text { tolerance and high } \\
\text { performance in terms } \\
\text { Of resource utilization. }\end{array}$ \\
\hline $\begin{array}{l}\text { Virtual Machine } \\
\text { Scheduling for Improving } \\
\text { Energy Efficiency in } \\
\text { IAAS Cloud }\end{array}$ & VM-Mig algorithm & $\begin{array}{l}\text { Number of VM } \\
\text { Total energy } \\
\text { consumption } \\
\text { Changing traffic } \\
\text { between VM }\end{array}$ & $\begin{array}{l}\text { This paper reduces the } \\
\text { Quantity of physical } \\
\text { resources to save energy } \\
\text { Consumption }\end{array}$ \\
\hline
\end{tabular}




\section{CONCLUSION}

In cloud computing, there were numerous services are providing on demand service provisioning is the main feature in IAAS. Scheduling is to provide the service and to reach the end user on time. Various techniques for efficiently schedule the task are discussed in this paper. So in this paper, our focus is basically on how effectively schedule the task to finish it off with accuracy and correctness. We have also discussed process of scheduling and the algorithms. In this paper various problems are surveyed and their solutions are discussed.

\section{REFERENCES}

[1] Jianying Luo, Lei Rao, and Xue Liu "Temporal Load Balancing with Service Delay Guarantees for Data Center Energy Cost Optimization", IEEE transactions on parallel and distributed systems, Vol. 25, No. 3, March 2014.

[2] Liang Zhou and Zhen Yang, "Exploring blind online scheduling for mobile cloud multimedia services", IEEE Wireless Communications, June 2013.

[3] Xiaomin Zhu, Laurence T. Yang, Huangke Chen, Ji Wang, Shu Yin and Xiaocheng Liu," Real-Time Tasks Oriented Energy-Aware Scheduling In Virtualized Clouds", IEEE Transactions On Cloud Computing, Vol. 2/April-June 2014.

[4] JRui Zhang, Kui Wu "Online Resource Scheduling Under Concave Pricing for Cloud Computing", IEEE Transactions On Parallel And Distributed Systems Vol. 27, No. 4, April 2016.

[5] Chun-Wei Tsai, Wei-Cheng Huang "A Hyper-Heuristic Scheduling Algorithm for Cloud", IEEE Transactions On cloud Computing, Vol. 2, No. 2, April-June 2014.

[6] Zhaomeng Zhu, Gongxuan Zhang "Evolutionary Multi-Objective Workflow Scheduling in Cloud", IEEE Transactions On Parallel And Distributed Systems, Vol. 27, No. 5, May 2016.

[7] Xiaomin Zhu, Member "ANGEL: Agent-Based Scheduling for Real-Time Tasks in Virtualized Clouds”, IEEE Transactions On Computers, Vol. 64, No. 12, December 2015.

[8] Chao Zhang "VGASA: Adaptive Scheduling Algorithm of Virtualized GPU Resource in Cloud Gaming", IEEE Transactions On Parallel And Distributed Systems, Vol. 25, No. 11, November 2014.

[9] S. Suresh Hao Huang "Scheduling In Compute Cloud With Multiple Data Banks Using Divisible Load Paradigm", IEEE Transactions On Aerospace And Electronic Systems, Vol. 51, No. 2 April 2015

October 11, 2014.

[10] Zhaomeng Zhu, Gongxuan Zhang, Miqing Li, and Xiaohui Liu "Evolutionary Multi-Objective Workflow Scheduling in Cloud", IEEE Transactions On Parallel And Distributed Systems, Vol. 27, No. 5, May 2016.

[11] Xue Lin, Yanzhi Wang, Qing Xie,” Task Scheduling with Dynamic Voltage and Frequency Scaling for Energy Minimization in the Mobile Cloud Computing Environment", IEEE Transactions On Services Computing, Vol. 8, No. 2, March/April 2015.

[12] Xingquan Zuo, Guoxiang Zhang, and Wei Tan, "Self-Adaptive Learning PSO-Based Deadline Constrained Task Scheduling for Hybrid iaas Cloud", IEEE Transactions On Automation Science And Engineering, Vol. 11, No. 2, April 2014.

[13] Chunsheng Zhu, Victor C. M. Leung, Laurence T. Yang, and Lei Shu "Collaborative Location-Based Sleep Scheduling for Wireless Sensor Networks Integrated With Mobile Cloud Computing", IEEE Transactions On Computers, Vol. 64, No. 7, July 2015. 
[14] Maria Alejandra Rodriguez and Rajkumar Buyya "Deadline Based Resource Provisioning and Scheduling Algorithm for Scientific Workflows on Clouds", IEEE Transactions On Cloud Computing, Vol. 2, No. 2, April-June 2014.

[15] Xiang Deng, Di Wu, Junfeng Shen, and Jian He, "Eco-Aware Online Power Management and Load Scheduling for Green Cloud Datacenters", IEEE Systems Journal, Vol. 10, No. 1, March 2016.

[16] Ji Wang, Weidong Bao, Xiaomin Zhu, Laurence T. Yang, and Yang Xiang, "FESTAL: Fault-Tolerant Elastic Scheduling Algorithm for Real-Time Tasks in Virtualized Clouds", IEEE Systems Journal, Vol. 10, No. 1, March 2016.

[17] Chun-Wei Tsai and Joel J. P. C. Rodrigues, "Metaheuristic Scheduling for Cloud: A Survey", IEEE Systems Journal, Vol. 8, No. 1, March 2014.

[18] Marco Polverini, Antonio Cianfrani, Shaolei Ren and Athanasios V. Vasilakos "Thermal-Aware Scheduling of Batch Jobs in Geographically Distributed Data Centers" ,IEEE Transactions On Cloud Computing, Vol. 2, No. 1, January-March 2014.

[19] Dong Jiankang, Wang Hongbo, Li Yang yang, Cheng Shiduan,"Virtual Machine Scheduling For Improving Energy Efficiency In Iaas Cloud", China Communications, March 2014.

Carlo Mastroianni, MichelaMeo, and Giuseppe Papuzzo," Probabilistic Consolidation Of Virtual Machines In Self-Organizing Cloud Data Centers", IEEE Transactions On Cloud Computing, Vol. 1, No. 2, July-December 2013. 